\title{
Doxycycline hyclate mediated silver-silver chloride nanoparticles and their antibacterial activity
}

\author{
Maheshkumar Prakash Patil ${ }^{1}$ (1) $\cdot$ Lei Lottice Anne Piad $^{2} \cdot$ Enkhnaran Bayaraa $^{2} \cdot$ Paul Subedi $^{2}$. \\ Naresh Hiralal Tarte ${ }^{2}$ (D) Gun-Do Kim ${ }^{3}(\mathbb{0}$
}

Received: 29 November 2018 / Accepted: 30 January 2019 / Published online: 8 February 2019

(c) The Author(s) 2019

\begin{abstract}
In the present work, we used doxycycline hyclate (DX) and tetramethylguanidine (TMG) for the synthesis of silver-silver chloride nanoparticles (DX-Ag- $\mathrm{AgCl} \mathrm{NPs}$ ) as a simple method for the production of nanoparticles (NPs). A new synthesis method for DX-Ag-AgCl NPs in aqueous medium, using the DX and TMG as a reducing and stabilizing agent, is reported. $\mathrm{DX}-\mathrm{Ag}-\mathrm{AgCl} \mathrm{NPs}$ were characterized by transmission electron microscopy. The elemental composition and the crystalline nature of synthesized nanoparticles were determined by energy-dispersive X-ray (EDX) spectroscopy and X-ray diffraction (XRD) analysis, respectively. From EDX, it is confirmed that synthesized NPs contain elemental silver and chloride, and their crystalline nature was confirmed by XRD. The Fourier transform infra-red spectra showed the DX present in surface of DX-Ag-AgCl NPs. Synthesized NPs analyzed for antibacterial activity by agar well method against Gram-positive and Gram-negative pathogens. Synthesized DX-Ag-AgCl NPs were spherical shaped and in the range of 10-40 nm of size was observed from TEM images. In the crystalline nature, XRD peaks indicate the presence of silver and silver chloride in produced NPs. Synthesized NPs show potential antibacterial activity on Bacillus cereus KCCM 11773, Bacillus subtilis KCCM 11316, Staphylococcus aureus KCCM 40050, Escherichia coli KCCM 11234, Klebsiella pneumoniae KCCM 11418, and Proteus vulgaris KCCM 40211.
\end{abstract}

Keywords Antibacterial · Doxycycline hyclate $\cdot$ Silver nanoparticles $\cdot$ Silver-silver chloride nanoparticles ·

Tetramethylguanidine

\section{Introduction}

Nanotechnology is emerging as the fastest growing technology and interdisciplinary field for manufacturing of material on the nanoscale. In the recent years, interest in the synthesis of noble metal nanoparticles (NPs) has increased due to their significant applications in different fields $[1,2]$. Nanoparticle synthesis is currently being focused on in the scientific

Gun-Do Kim

gundokim@pknu.ac.kr

1 Research Institute for Basic Sciences, Pukyong National University, 45 Yongso-ro, Nam-gu, Busan 48513, Republic of Korea

2 Korea Science Academy of KAIST, 105-47, Baegyang gwanmum-ro, Busanjin-gu, Busan 47162, Republic of Korea

3 Department of Microbiology, College of Natural Sciences, Pukyong National University, 45 Yongso-ro, Nam-gu, Busan 48513, Republic of Korea community for the process is simple, rapid, and eco-friendly $[3,4]$. Nowadays, nanotechnology is an active domain for the synthesis of nanoparticles through the use of natural resources like plants and microorganisms [5, 6]. Nanoparticles have significant importance in biomedical applications including antimicrobial, antioxidant, anticancer activities, and many more [7-10]. The silver nanoparticles (AgNPs) have emerged in recent decades as a useful chemical tool, due to their broad applications in microbiology $[11,12]$ and biomedicine [13, 14].

Different antibiotics have been reported for the synthesis of AgNPs such as, ampicillin [15], tetracycline [16], tobramycin [17], and amoxicillin [18]. Drug resistance is a major challenge, needed to develop new biomedicine to treat drug resistance pathogens without harming the normal cells [19]. Inorganic nanomaterials in the form of nanoparticles such as $\mathrm{Ag}$, silver chloride $(\mathrm{AgCl})$, and silver-silver chloride $(\mathrm{Ag}-\mathrm{AgCl})$ could be alternative drug to control pathogenic microbial infections. Ag NPs are metal NPs containing only 
silver [20], $\mathrm{AgCl} \mathrm{NPs}$ are inorganic NPs containing silver and chloride ions [21], and $\mathrm{Ag}-\mathrm{AgCl} \mathrm{NPs}$ are composite NPs containing $\mathrm{Ag}$ and $\mathrm{AgCl}$ NPs [22]. The antibacterial activity of AgNPs has been well established [11, 12]. AgNPs target different sites in bacteria and inhibit their growth [5]. From the literatures, AgNPs arrest microbial growth by targeting different sites such as direct binding to cell surface which causes membrane damage, changes in cell membrane permeability, leakage of cell constituents [11, 12, 23], formation of reactive oxygen species [24, 25], and inhibition of vital proteins [26]. All these interactions of AgNPs with microorganisms are responsible for the inhibition or killing of microorganisms. Metal nanoparticles with antibiotics show enhanced bactericidal activity, and can be the alternative hybrid drug for the overcoming of multidrug-resistant bacterial infection $[16,17]$.

Here, we report a simple, one-pot, and rapid method for the synthesis of DX-Ag- $\mathrm{AgCl}$ NPs using doxycycline hyclate (DX) and tetramethylguanidine (TMG). The synthesized $\mathrm{Ag}-\mathrm{AgCl}$ NPs were characterized using different techniques such as the UV-visible spectrophotometer, transmission electron microscope (TEM), energy-dispersive X-ray diffraction (EDX), X-ray diffraction (XRD), and Fourier transform infra-red spectroscopy (FT-IR). The synthesized NPs were evaluated for antibacterial activity on Gram-positive (Bacillus cereus KCCM 11773, Bacillus subtilis KCCM 11316, and Staphylococcus aureus KCCM 40050) and Gram-negative (Escherichia coli KCCM 11234 , Klebsiella pneumoniae KCCM 11418, and Proteus vulgaris KCCM 40211) pathogenic bacteria by agar well-diffusion and broth microdilution method.

\section{Materials and methods}

\section{Materials}

Silver nitrate $\left(\mathrm{AgNO}_{3}\right)$ was purchased from Fisher Scientific (New Jersey, USA). Doxycycline hyclate (DX), 1,1,3,3-tetramethylguanidine (TMG), and iodonitrotetrazolium chloride (INT) were purchased from Sigma-Aldrich (USA). Mueller-Hinton Broth (MHB) and Mueller-Hinton Agar (MHA) were obtained from BD Diagnostic, France. The 96-well plate was supplied by SPL Life science, Gyeonggi, Korea.

\section{Synthesis of DX-Ag-AgCI NPs}

$\mathrm{AgNO}_{3}(1 \mathrm{mM}), \mathrm{DX}\left(50 \mathrm{mg} \mathrm{mL}^{-1}\right)$ and TMG $\left(50 \mathrm{mg} \mathrm{mL}^{-1}\right)$ solutions were prepared in triple distilled water. In a $10 \mathrm{~mL}$ of $\mathrm{AgNO}_{3}$ solution, $20 \mu \mathrm{L}$ of DX and $40 \mu \mathrm{L}$ of TMG were added, and the reaction was performed at $80{ }^{\circ} \mathrm{C}$ for $5 \mathrm{~min}$ with continuous stirring. Immediately after the reaction, the solution was cooled under running tap water. Separation of prepared NPs was performed by high-speed centrifugation (12,000 rpm, $30 \mathrm{~min})$ and unbounded materials were removed by washing with distilled water twice. For characterization, powder form of $\mathrm{DX}-\mathrm{Ag}-\mathrm{AgCl} \mathrm{NPs}$ obtained by lyophilization.

\section{Characterization of DX-Ag-AgCl NPs}

DX-Ag- $\mathrm{AgCl}$ NPs were observed visually, while the absorbance spectra were recorded by Jasco V-670 UV-Vis spectrophotometer (Japan) in the range of 300-800 nm during all reactions. Characterization of synthesized NPs was performed as per procedure reported previously [27, 28]. In brief, the morphological features such as the size, shape, and distribution of DX-Ag- $\mathrm{AgCl}$ NPs were observed through TEM, and, for the sample preparation, colloidal suspension was dropped on a copper disk and then dried at room temperature. TEM (Hitachi, H7500, Tokyo, Japan) images captured at $120 \mathrm{kV}$. Lyophilized DX-Ag-AgCl NPs were used to determine the elemental composition and crystalline nature by EDX spectroscopy and XRD, respectively. XRD (Philips X'Pert-MPD Diffractometer, Netherland) was operated at $40 \mathrm{kV}$ and $30 \mathrm{~mA}$ using $\mathrm{Cu} \mathrm{K} \alpha$ radiations. Fourier transform infra-red (FT-IR) spectra were obtained in transmission mode on powdered DX and lyophilized DX-Ag- $\mathrm{AgCl}$ NPs that were mixed with dry $\operatorname{KBr}(1: 100)$ and compressed into a thin pellet film. The NPs zeta potential and particlesize analysis (PSA) were analyzed by electrophoretic light scattering spectrophotometer (ELS-8000, OTSUKA Elec., Osaka, Japan). Samples for zeta potential and PSA analysis were prepared/diluted in tripled distilled water [23]. FT-IR (Nicolet iS 10, Thermo Electron Scientific Inst. LLC, Fitchburg, WI, USA) spectra in the range of $4000-500 \mathrm{~cm}^{-1}$ were obtained to determine the involvement of functional groups [28].

\section{Antibacterial activity}

The pathogenic Gram-positive (B. cereus KCCM 11773, B. subtilis KCCM 11316, and S. aureus KCCM 40050) and Gram-negative (E. coli KCCM 11234, K. pneumoniae KCCM 11418, and P. vulgaris KCCM 40211) bacterial strains used in this study were purchased from the Korean Culture Center of Microorganisms (KCCM), Republic of Korea. Agar well-diffusion method, minimum inhibitory concentration (MIC), and minimum bactericidal concentration (MBC) for DX and DX-Ag- $\mathrm{AgCl}$ NPs were performed as per previously published report [28].

\section{Agar well-diffusion method}

A single colony of bacterial strain was inoculated in $20 \mathrm{~mL}$ of the MHB broth and grown at $37{ }^{\circ} \mathrm{C}$ overnight. 
An overnight culture, $0.5 \mathrm{McFarland}$-standard bacterial

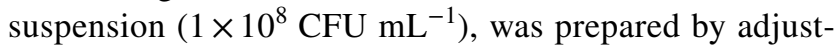
ing optical density (OD) to around 0.08-0.1, and then used for agar well-diffusion method. $\mathrm{OD}_{600}$ was obtained using a spectrophotometer (Libra S22, Biochrom Ltd, Cambridge, England). $100 \mu \mathrm{L}$ of bacterial suspension spreaded over MHA plate with the help of sterile glass spreader, while the wells were prepared using $8 \mathrm{~mm}$ cork borer. $100 \mu \mathrm{L}$ of DX and DX-Ag- $\mathrm{AgCl}$ NPs stock solutions $\left(1 \mathrm{mg} \mathrm{mL}^{-1}\right)$ were dropped in wells, and plates were incubated at $37{ }^{\circ} \mathrm{C}$ for $24 \mathrm{~h}$. After incubation, the zone of inhibition (ZOI) diameter was measured in $\mathrm{mm}$. These experiments were performed in triplicate.

\section{Determination of MIC and MBC}

The MIC and MBC were performed by broth microdilution and spread plate method, respectively. A $0.5 \mathrm{McF}$ arlandstandard adjusted bacterial suspension $\left(1 \times 10^{8} \mathrm{CFU} \mathrm{mL}^{-1}\right)$ was diluted with 1:100 ratios in MHB to obtain $1 \times 10^{6} \mathrm{CFU} \mathrm{mL}{ }^{-1}$. In broth microdilution method, each well of 96-well plate contained $50 \mu \mathrm{L}$ of DX and DX-Ag- $\mathrm{AgCl}$ NPs with different concentrations $(0.5,1,2,4,6,8,10,12$, 14 , and $16 \mu \mathrm{g} \mathrm{mL}^{-1}$ ) and $50 \mu \mathrm{L}$ of each bacterial strain suspension $\left(1 \times 10^{6} \mathrm{CFU} \mathrm{mL}{ }^{-1}\right)$ were added separately. Two sets of 96-well plate were prepared: one for MIC and another for MBC determination. Negative control was prepared, which contained only media; while the positive control contained bacterial strains without DX or DX-Ag- $\mathrm{AgCl}$ NPs. Plates were incubated for $24 \mathrm{~h}$ at $37^{\circ} \mathrm{C}$. After that, in one 96-well plate, $40 \mu \mathrm{L}$ of INT $\left(0.2 \mathrm{mg} \mathrm{mL}^{-1}\right)$ solution was added to each well. The plate was further incubated for $30 \mathrm{~min}$, to interaction of INT with enzyme dehydrogenase. Pink color formation can be seen in the presence of live cells, while there will be no color change in dead cells. The lowest dilution without color change will be indicated as the MIC. From the second plate, $100 \mu \mathrm{L}$ of MIC concentrations was plated on MHA plate and spread with sterile glass spreader. These plates were incubated for $24 \mathrm{~h}$ at $37^{\circ} \mathrm{C}$. After incubation, MBC will be recorded as the lowest concentration of DX or DX-Ag- $\mathrm{AgCl} \mathrm{NPs}$ that resulted in no bacterial growth.

\section{Results and discussion}

\section{Characterization of DX-Ag-AgCl NPs}

\section{UV-visible spectroscopy}

The reactions were carried out at boiling temperature to promote $\mathrm{AgNO}_{3}$ reduction. A typical reaction solution contained $10 \mathrm{~mL}$ of $\mathrm{AgNO}_{3}(1 \mathrm{mM}), 20 \mu \mathrm{L}$ of DX $\left(50 \mathrm{mg} \mathrm{mL}^{-1}\right)$, and $40 \mu \mathrm{L}$ of TMG $\left(50 \mathrm{mg} \mathrm{mL}^{-1}\right)$ solution. Reaction was performed at $80{ }^{\circ} \mathrm{C}$ for $5 \mathrm{~min}$. During reaction, the formation of $\mathrm{DX}-\mathrm{Ag}-\mathrm{AgCl} \mathrm{NPs}$ was observed by change in the color of the solution. After reaction, brown color formation was observed and characteristic sharp peak at $407 \mathrm{~nm}$ in UV-visible spectroscopy was observed, as shown in Fig. 1. AgNPs shows characteristic peak, and the surface plasmon resonance (SPR) absorption band is strongly depending on the NPs size, surrounding chemicals and dielectric medium $[29,30]$. The SPR peak towards shorter wavelength indicates decreased size of NPs [29]. Our findings are in good agreement with these reports.

\section{Elemental and crystalline nature of nanoparticles}

The DX-Ag-AgCl NPs synthesized by addition of $40 \mu \mathrm{L}$ of TMG and $20 \mu \mathrm{L}$ of DX in $10 \mathrm{~mL}$ of $1 \mathrm{mM} \mathrm{AgNO}_{3}$ solution, and reaction was performed at $80^{\circ} \mathrm{C}$ for 5 min with continuous stirring; TMG and DX solutions were prepared in distilled water with concentration of $50 \mathrm{mg} \mathrm{mL}^{-1}$. Synthesized NPs was lyophilized for further characterization.

Figure 2 indicates the EDX spectrum, obtained from lyophilized NPs by EDX on FE-SEM. The EDX analysis confirms the presence of elements in the synthesized DX-Ag- $\mathrm{AgCl}$ NPs. The EDX spectrum shows two signals at 2.7 and $3.0 \mathrm{keV}$, which correspond to the $\mathrm{Cl}$ and $\mathrm{Ag}$, respectively. The characteristic presence of element, $\mathrm{Cl}$ and $\mathrm{Ag}$, in EDX spectrum confirms the composition of the $\mathrm{Ag}-\mathrm{AgCl}$ NPs as being consistent with the previous reports [23, 28].

Figure 3 illustrates the XRD diffraction patterns for DX-Ag-AgCl NPs. Nine peaks were detected on the XRD pattern, with five peaks corresponding to $\mathrm{AgCl}$ and four to AgNPs. The diffraction peaks at $2 \theta=27.96^{\circ}, 32.35^{\circ}$, $46.26^{\circ}, 54.97^{\circ}$, and $57.61^{\circ}$ correspond to the diffractions from $\{111\},\{200\},\{220\},\{311\}$, and $\{222\}$ planes of a

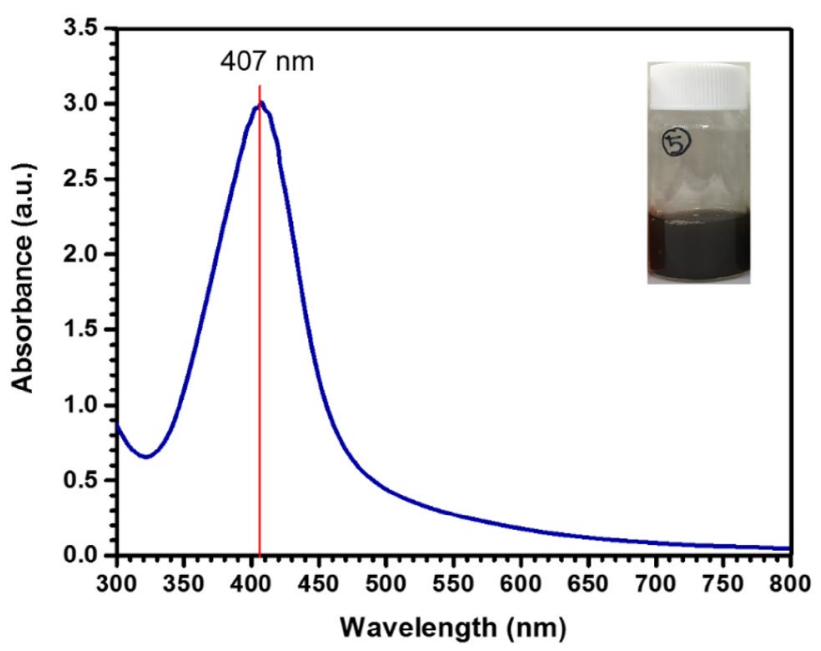

Fig. 1 Ultraviolet-visible spectroscopy of $\mathrm{DX}-\mathrm{Ag}-\mathrm{AgCl}$ NPs synthesized using $\mathrm{AgNO}_{3}$, TMG, and DX 


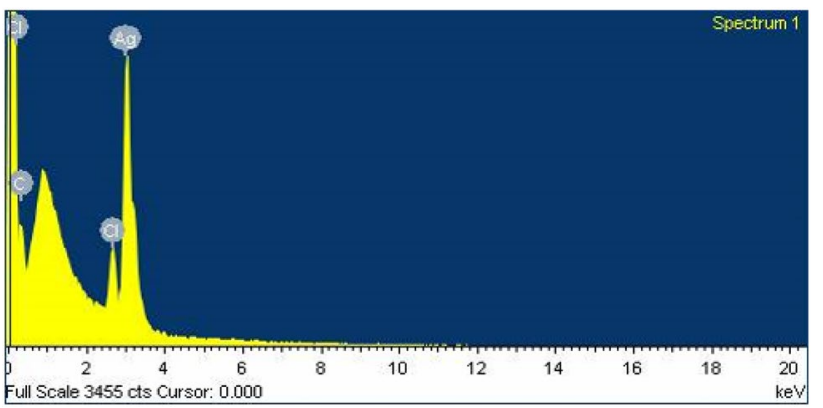

Fig. 2 Energy-dispersive X-ray diffraction spectrum of $\mathrm{DX}-\mathrm{Ag}-\mathrm{AgCl}$ NPs synthesized using DX and TMG

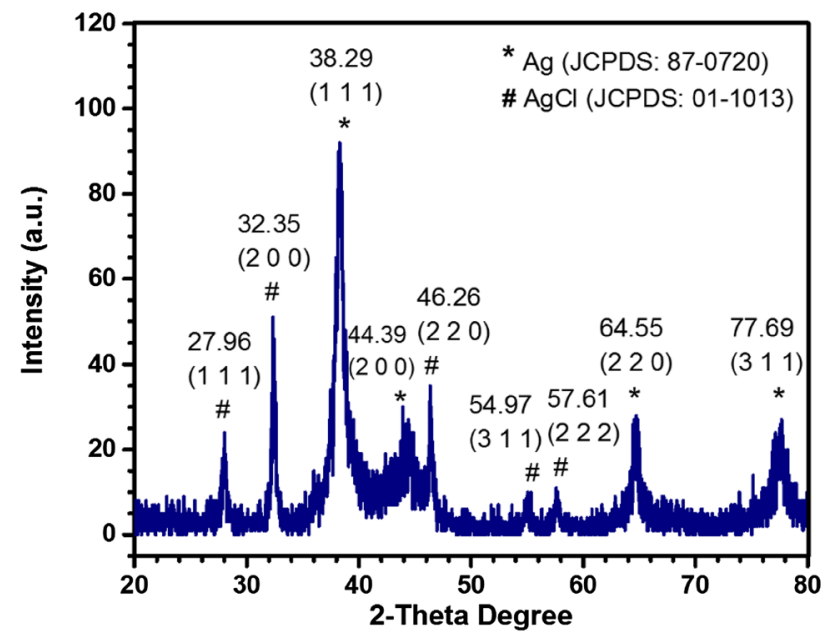

Fig. 3 X-ray diffraction patterns of $\mathrm{Ag}$ and $\mathrm{AgCl}$ NPs synthesized using DX and TMG

face-centered cubic (FCC) $\mathrm{AgCl}$, respectively. Furthermore, diffraction peaks at $2 \theta=38.29^{\circ}, 44.39^{\circ}, 64.55^{\circ}$, and $77.69^{\circ}$ correspond to the diffractions from $\{111\},\{200\},\{220\}$, and $\{311\}$ planes of a FCC Ag, respectively. The bars (FCC planes) in the graph are from the Joint Committee on Powder Diffraction Standards (JCPDS) reference diffraction files for $\mathrm{Ag}$ (\#87-0720) and $\mathrm{AgCl}$ (\#01-1013). The crystalline nature of DX-Ag-AgCl NPs was confirmed by XRD.

The crystalline size of DX-Ag- $\mathrm{AgCl}$ NPs was calculated by Debye-Scherrer's equation as follows:

$D=\frac{K \lambda}{\beta \cos \theta}$,

where $D$ is the crystalline size in $\mathrm{nm}, K$ is the Scherrer's constant $(K=0.94), \lambda$ is the wavelength of incident X-ray, $\beta$ is the full width at half maximum (FWHM) of the diffraction peak, and $2 \theta$ is the diffraction angle. The major five diffraction peaks, viz, 32.35, 38.29, 46.26, 64.55, and 77.69 corresponding to (200), (111), (220), (200), and (311) hkl planes, were considered for the determination of average particle size of NPs [31]. XRD spectra revealed highly crystallinity, and the average crystalline particle size of DX-Ag- $\mathrm{AgCl} \mathrm{NPs}$ was found $8.25 \mathrm{~nm}$ which was calculated by Debye-Scherrer's formula. The plausible reaction mechanism for formation of $\mathrm{AgCl} \mathrm{NPs}$ is presented in Scheme 1. These results are compatible with the previous reports of $\mathrm{Ag}$ and $\mathrm{AgCl}$ NPs synthesis using biological methods [23, 28] and chemical method [32].

\section{Morphology of nanoparticles}

The shape, size, and distribution of the DX-Ag- $\mathrm{AgCl}$ NPs were observed by TEM. In Fig. 4, the TEM image reveals the synthesized NPs mostly spherical, and polydisperse. In addition, the particle size was found to be in the range of $10-40 \mathrm{~nm}$ for $\mathrm{DX}-\mathrm{Ag}-\mathrm{AgCl} \mathrm{NPs}$. The polydisperse nature of NPs is due to the formation of $\mathrm{Ag}$ and $\mathrm{AgCl}$ NPs. These patterns were found to be well in agreement with those observed from XRD peaks and demonstrate the crystalline nature.

\section{Zeta potential and particle size of nanoparticles}

Zeta potential analysis was applied to determine the surface overall charges on NPs [23]. The zeta potential value of synthesized DX-Ag- $\mathrm{AgCl} \mathrm{NPs}$ is $-5.01 \mathrm{mV}$ (shown in Fig. 5), which indicates negative charges on the NPs. Distilled water were used as a dispersion medium for zeta potential and PSA analysis. Figure 6 indicates the histogram of synthesized DX-Ag- $\mathrm{AgCl}$ NPs' particle-size distribution. From PSA analysis, it is observed that maximum NPs are in range of 5-20 nm. This observation is compatible with NPs' size observed in TEM image.

\section{Nanoparticle surface study by Fourier transform infra-red (FT-IR) spectroscopy}

The FT-IR measurement was carried out to determine the presence of biomolecules on the nanoparticles copping layer. In Fig. 7, the FT-IR spectra of DX and DX-Ag- $\mathrm{AgCl}$ NPs suggested extensive similarities between the samples. From the FT-IR studies, the characteristic bands for functional groups of DX were identified, including $\mathrm{O}-\mathrm{H}$ group at $3318 \mathrm{~cm}^{-1}, \mathrm{C}=\mathrm{O}$ group at $1683 \mathrm{~cm}^{-1}$, and $\mathrm{N}-\mathrm{H}$ group at $1573 \mathrm{~cm}^{-1}$. In particular, the characteristic bands of DX at $1650 \mathrm{~cm}^{-1}$ region related to the $\mathrm{NH}_{2}$ group, which is known to interact with $\mathrm{HCl}$, cause a decrease in transmittance intensity. On the other hand, the DX-Ag- $\mathrm{AgCl}$ NPs sample had a more intense peak at $1650 \mathrm{~cm}^{-1}$ which corroborate the fact that $\mathrm{HCl}$ has been removed from the molecular complex and DX transformed to doxycycline monohydrate [33]. Formation of the doxycycline monohydrate from DX is presented 

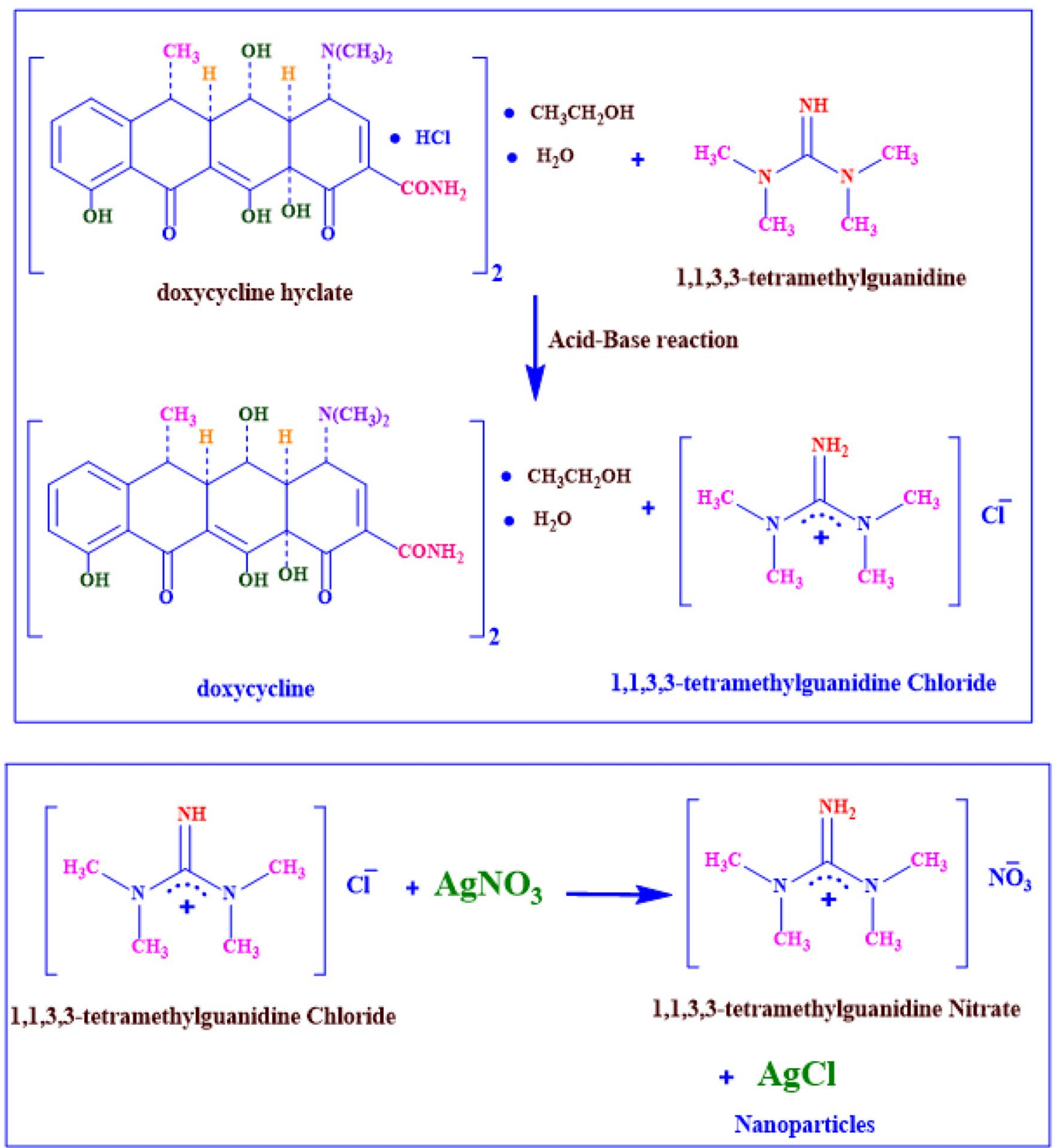

Scheme 1 The possible reaction mechanism for synthesis of DX-Ag-AgCl NPs using DX and TMG

in Scheme 1. The present study results are compatible with these results.

\section{Plausible mechanism of DX-Ag-AgCl NPs formation}

The plausible formation of $\mathrm{AgCl}$ NPs can be best explained on the basis of Scheme 1. Here, the DX is the source of $\mathrm{H}^{+}$ (via $\mathrm{HCl}$ ) which, under the reaction conditions, can react with the TMG to produce the Lewis adduct and chloride anion. The chloride anion thus formed reacts with the free $\mathrm{Ag}^{+}$in aqueous medium forming the $\mathrm{AgCl}$ NPs. However, the formation of $\mathrm{Ag}$ NPs can be best explained on the basis of hypothetical mechanism reported previously, by the functional groups $(-\mathrm{OH})$ similarity of the DX with quercetin in the leaf extract [34].

\section{Antibacterial activity of DX-Ag-AgCl NPs}

As a potential application, the DX-functionalized $\mathrm{Ag}-\mathrm{AgCl} \mathrm{NPs}$ were tested as a bactericidal. Antibacterial activity was performed by agar well-diffusion method against Gram-positive (B. cereus KCCM 11773, B. subtilis KCCM 11316, and S. aureus KCCM 40050) and Gramnegative (E. coli KCCM 11234, K. pneumoniae KCCM 


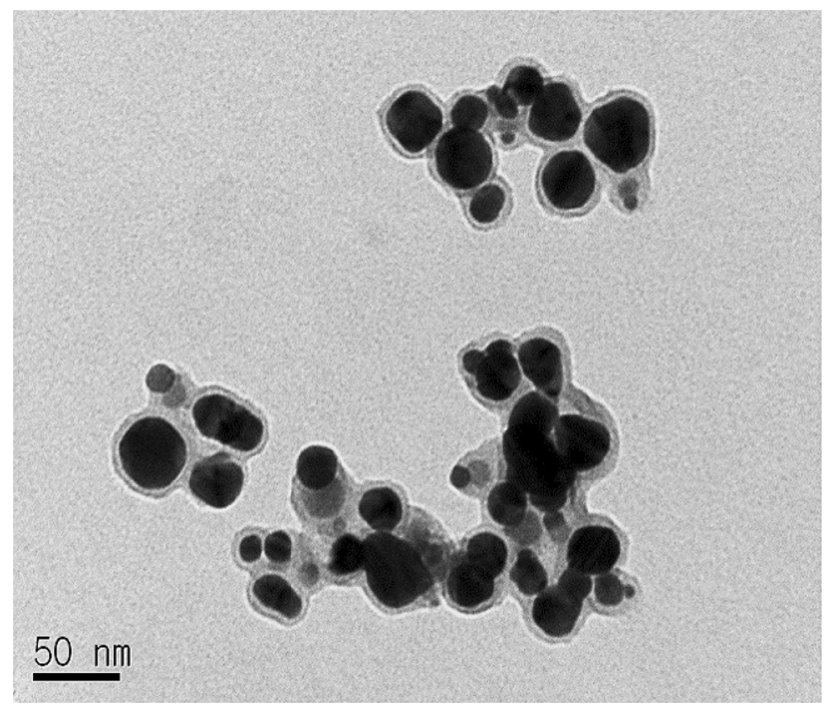

Fig. 4 Transmission electron microscopy image of $\mathrm{DX}-\mathrm{Ag}-\mathrm{AgCl} \mathrm{NPs}$

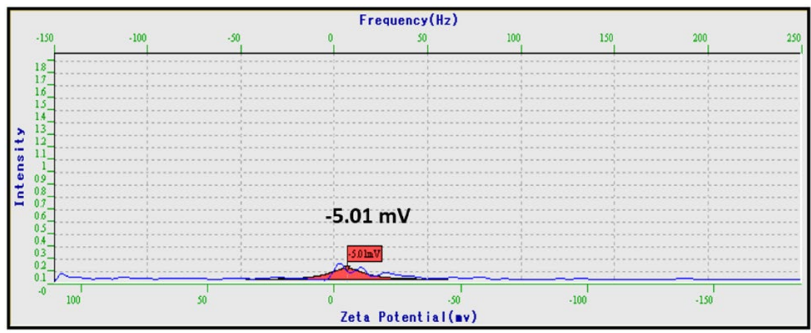

Fig. 5 Zeta potential report of $\mathrm{DX}-\mathrm{Ag}-\mathrm{AgCl}$ NPs synthesized using TMG and DX

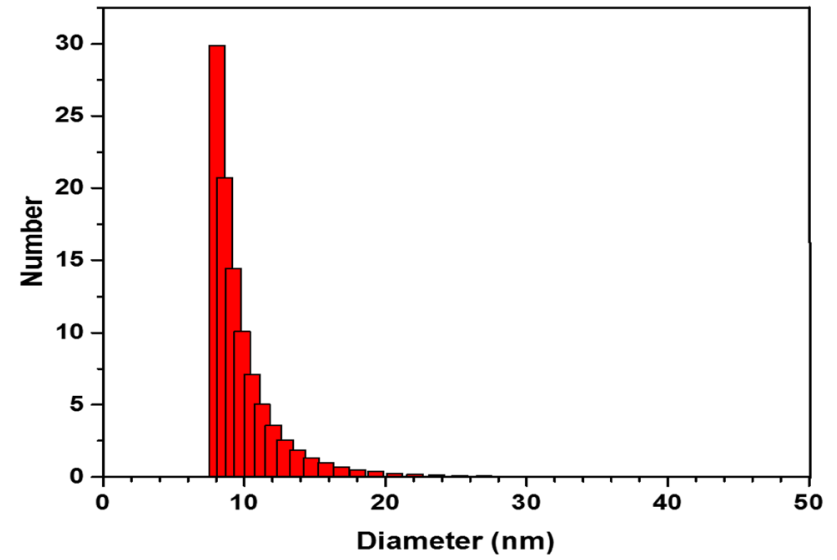

Fig. 6 Particle-size analysis of $\mathrm{DX}-\mathrm{Ag}-\mathrm{AgCl} \mathrm{NPs}$ synthesized using TMG and DX

11418, and P. vulgaris KCCM 40211) pathogenic bacteria. The antibacterial activity of DX and DX-Ag-AgCl NPs was observed after $24 \mathrm{~h}$. Figure 8 shows the antibacterial

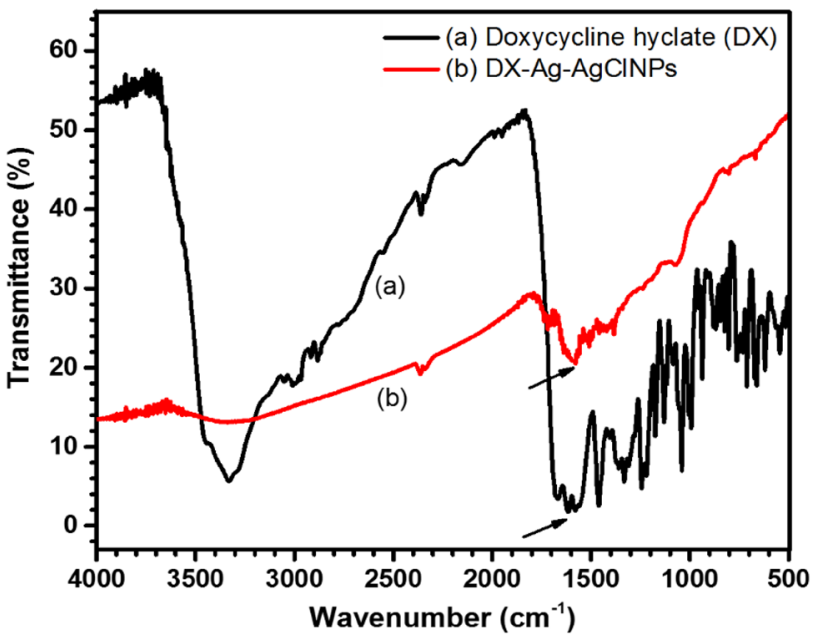

Fig. 7 Fourier transform infra-red spectroscopy of a synthesized DX-Ag- $\mathrm{AgCl}$ NPs and $\mathbf{b}$ antibiotic DX

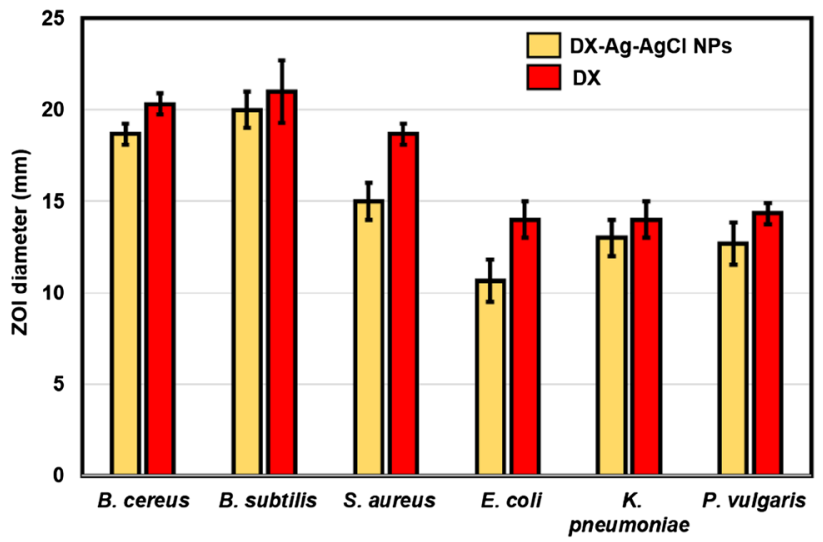

Fig. 8 Antibacterial activity of the DX-Ag- $\mathrm{AgCl}$ NPs and DX against pathogenic bacteria

activity of synthesized DX-Ag- $\mathrm{AgCl}$ NPs compared with pure DX. The variation in the ZOI was noticed with respect to the type of bacterium, which might be due to the difference in the bacterial surface characteristics. Grampositive and Gram-negative bacteria differ in several ways when looking at the cell wall. Gram-positive bacteria have a thick, multi-layered peptidoglycan (negatively charged), virtually none of lipopolysaccharide and presence of teichoic acid; Gram-negative bacteria have a thin singlelayered peptidoglycan, which contains high lipopolysaccharides and absence of teichoic acid. All these different cell surface compositions make differences in the sensitivity of bacteria to NPs and antibiotics $[35,36]$. Table 1 shows the MIC and MBC of DX-Ag-AgCl NPs and DX, which was obtained against Gram-positive and Gramnegative pathogens. From these results, it is observed that the growth inhibition of Gram-positive (B. cereus 
Table 1 Antibacterial effect of DX-Ag-AgCl NPs and DX on pathogenic bacterial strains

\begin{tabular}{|c|c|c|c|c|}
\hline \multirow[t]{3}{*}{ Bacterial strains } & \multicolumn{4}{|c|}{$\mu \mathrm{g} \mathrm{mL} L^{-1}$} \\
\hline & \multicolumn{2}{|c|}{$\begin{array}{l}\mathrm{DX}-\mathrm{Ag}- \\
\mathrm{AgCl} \text { NPs }\end{array}$} & \multicolumn{2}{|l|}{ DX } \\
\hline & MIC & $\mathrm{MBC}$ & MIC & MBC \\
\hline \multicolumn{5}{|l|}{ Gram-positive } \\
\hline Bacillus cereus KCCM 11773 & 1 & 1 & 0.5 & 1 \\
\hline Bacillus subtilis KCCM 11316 & 2 & 2 & 0.5 & 1 \\
\hline Staphylococcus aureus KCСM 40050 & 8 & 10 & 6 & 6 \\
\hline \multicolumn{5}{|l|}{ Gram-negative } \\
\hline Escherichia coli KCCM 11234 & 8 & 12 & 4 & 8 \\
\hline Klebsiella pneumoniae КССМ 11418 & 4 & 8 & 4 & 4 \\
\hline Proteus vulgaris KCCM 40211 & 1 & 2 & 0.5 & 2 \\
\hline
\end{tabular}

KCCM 11773) bacteria inhibited at lowest concentration of DX-Ag-AgCl NPs (MBC, $1 \mu \mathrm{g} \mathrm{mL}^{-1}$ ), while Gram-negative (E. coli KCCM 11234) bacteria inhibited at higher concentration of DX-Ag-AgCl NPs (MBC, $12 \mu \mathrm{g} \mathrm{mL}{ }^{-1}$ ). When the antibacterial effect of the DX-functionalized NPs is compared with that of DX alone, the amount of DX required is equal or considerably lower. These findings are in good agreement with the reported studies [16, 37, 38]. AgNPs are effective antibacterial agent, which cause adverse toxic effect on bacterial cells [8]. It is well known that the antibacterial activity of AgNPs is dependent on their size and shape; smaller AgNPs shows more bactericidal activity due to their more surface-to-volume ratio $[11,39]$.

\section{Conclusions}

The study of a simple method for the synthesis of DX-Ag- $\mathrm{AgCl}$ NPs using DX and TMG, which has an antibacterial activity against Gram-positive and Gram-negative pathogens, has been described here for the first time. Using the developed methodology, DX-Ag-AgCl NPs are synthesized rapidly, in $5 \mathrm{~min}$. The synthesized NPs were spherical shaped with a size of $10-40 \mathrm{~nm}$, and contained $\mathrm{Ag}$ and $\mathrm{AgCl}$. Further studies are required for the synthesis of NPs with improved functions, and controlled shape and size. Applications of NPs based on these findings may lead to valuable discoveries in different fields such as medical devices and antibacterial systems.

Acknowledgements This research was supported by Basic Science Research Program through the National Research Foundation of Korea (NRF) funded by the Ministry of Education (2018R1D1A1B07043388) and also supported by the Research and Education Program at Korea
Science Academy of KAIST with funds from the Ministry of Science, ICT and Future Planning (Year 2018).

\section{Compliance with ethical standards}

Conflict of interest The authors declare no conflict of interest. The funders had no role in the design of the study; in the collection, analyses, or interpretation of data; in the writing of the manuscript, or in the decision to publish the results.

Open Access This article is distributed under the terms of the Creative Commons Attribution 4.0 International License (http://creativecommons.org/licenses/by/4.0/), which permits unrestricted use, distribution, and reproduction in any medium, provided you give appropriate credit to the original author(s) and the source, provide a link to the Creative Commons license, and indicate if changes were made.

\section{References}

1. Jain, P.K., Huang, H., El-Sayed, I.H., El-Sayed, M.A.: Noble on the nanoscale: optical and photothermal properties and some applications in imaging, sensing, biology, and medicine. Acc. Chem. Res. 41, 1578-1586 (2008)

2. El-Nour, K.M.M.A., Eftaiha, A., Al-Warthan, A., Ammar, R.A.A.: Synthesis and application of silver nanoparticles. Arab. J. Chem. 3, 135-140 (2010)

3. Kharissova, O.V., Dias, H.V.R., Kharisov, B.I., Perez, B.O., Perez, V.M.J.: The greener synthesis of nanoparticles. Trends Biotechnol. 31, 240-248 (2013)

4. Hussain, I., Singh, N.B., Singh, A., Singh, H., Singh, S.C.: Green synthesis of nanoparticles and its potential applications. Biotechnol. Lett. 38, 545-560 (2016)

5. Patil, M.P., Kim, G.-D.: Eco-friendly approach for nanoparticles synthesis and mechanism behind antibacterial activity of silver and anticancer activity of gold nanoparticles. Appl. Microbiol. Biotechnol. 101, 79-92 (2017)

6. Patil, M.P., Kim, G.-D.: Marine microorganisms for synthesis of metallic nanoparticles and their biomedical applications. Colloids Surf. B 172, 487-495 (2018)

7. Schrofel, A., Kratosova, G., Safarik, I., Safarikova, M., Raska, I., Shor, L.M.: Applications of biosynthesized metallic nanoparticles-a review. Acta Biomater. 10, 4023-4042 (2014)

8. Kim, J.S., Kuk, E., Yu, K.N., Kim, J.-H., Park, S.J., Lee, H.J., Kim, S.H., Park, Y.K., Park, Y.H., Hwang, C.-Y., Kim, Y.-K., Lee, Y.-S., Jeong, D.H., Cho, M.-H.: Antimicrobial effects of silver nanoparticles. Nanomedicine. 3, 95-101 (2007)

9. Azizi, M., Sedaghat, S., Tahvildari, K., Derakhshi, P., Ghaemi, A.: Synthesis of silver nanoparticles using Peganum harmala extract as a green route. Green Chem. Lett. Rev. 10, 420-427 (2017)

10. Pugazhendhi, A., Edison, T.N.J.I., Karuppusamy, I., Kathirvel, B.: Inorganic nanoparticles: a potential cancer therapy for human welfare. Int. J. Pharm. 539, 104-111 (2018)

11. Morones, J.R., Elechiguerra, J.L., Camacho, A., Holt, K., Kouri, J.B., Ramirez, J.T., Yacaman, M.J.: The bactericidal effect of silver nanoparticles. Nanotechnology. 16, 2346-2353 (2005)

12. Rai, M., Yadav, A., Gade, A.: Silver nanoparticles as a new generation of antimicrobials. Biotechnol. Adv. 27, 76-83 (2009)

13. Chaloupka, K., Malam, Y., Seifalian, A.M.: Nanosilver as a new generation of nanoproduct in biomedical applications. Trends Biotechnol. 28, 580-588 (2010) 
14. Wei, L., Lu, J., Xu, H., Patel, A., Chen, Z.-S., Chen, G.: Silver nanoparticles: synthesis, properties, and therapeutic applications. Drug Discov. Today 20, 595-601 (2015)

15. Junejo, Y., Sirajuddin, S., Baykal, A., Safdar, M., Balouch, A.: A novel green synthesis and characterization of Ag NPs with its ultra-rapid catalytic reduction of methyl green dye. Appl. Surf. Sci. 290, 499-503 (2014)

16. Djafari, J., Marinho, C., Santos, T., Igrejas, G., Torres, C., Capelo, J.L., Poeta, P., Lodeiro, C., Fernandez-Lodeiro, J.: New synthesis of gold- and silver-based nano-tetracycline composites. ChemistryOpen. 5, 206-212 (2016)

17. Ullah, S., Ahmad, A., Subhan, F., Jan, A., Raza, M., Khan, A.U., Rahman, A.U., Khan, U.A., Tariq, M., Yuan, Q.: Tobramycin mediated silver nanospheres/graphene oxide composite for synergistic therapy of bacterial infection. J. Photochem. Photobiol. B 183, 342-348 (2018)

18. Junejo, Y., Guner, A., Baykal, A.: Synthesis and characterization of amoxicillin derived silver nanoparticles: its catalytic effect on degradation of some pharmaceutical antibiotics. Appl. Surf. Sci. 317, 914-922 (2014)

19. Levy, S.B., Marshall, B.: Antibacterial resistance worldwide: causes, challenges and responses. Nat. Med. 10, S122-S129 (2004)

20. Omidi, S., Sedaghat, S., Tahvildari, K., Derakhshi, P., Motiee, F.: Biosynthesis of silver nanoparticles with Adiantum capillusveneris $\mathrm{L}$ leaf extract in the batch process and assessment of antibacterial activity. Green Chem. Lett. Rev. 11, 544-551 (2018)

21. Dhas, T.S., Kumar, V.G., Karthick, V., Angel, K.J., Govindaraju, $\mathrm{K}$.: Facile synthesis of silver chloride nanoparticles using marine alga and its antibacterial efficacy. Spectrochim. Acta Part A 120, 416-420 (2014)

22. Eugenio, M., Campanati, L., Muller, N., Romao, L.F., Souza, J.D., Alves-Leon, S., Souza, W.D., Sant'Anna, C.: Silver/silver chloride nanoparticles inhibit the proliferation of human glioblastoma cells. Cytotechnology. 70, 1607-1618 (2018)

23. Patil, M.P., Seo, Y.B., Kim, G.-D.: Morphological changes of bacterial cells upon exposure of silver-silver chloride nanoparticles synthesized using Agrimonia pilosa. Microb. Pathog. 116, 84-90 (2018)

24. Carlson, C., Hussain, S.M., Schrand, A.M., Braydich-Stolle, L.K., Hess, K.L., Jones, R.L., Schlager, J.J.: Unique cellular interaction of silver nanoparticles: size-dependent generation of reactive oxygen species. J. Phys. Chem. 112, 13608-13619 (2008)

25. Park, H.-J., Kim, J.Y., Kim, J., Lee, J.-H., Hahn, J.-S., Gu, M.B., Yoon, J.: Silver-ion-mediated reactive oxygen species generation affecting bactericidal activity. Water Res. 43, 1027-1032 (2009)

26. Wigginton, N.S., Titta, A.D., Piccapietra, F., Dobias, J., Nesatyy, V.J., Suter, M.J.F., Bernier-Latmani, R.: Binding of silver nanoparticles to bacterial proteins depends on surface modifications and inhibits enzymatic activity. Environ. Sci. Technol. 44, 21632168 (2010)

27. Patil, M.P., Rokade, A.A., Ngabire, D., Kim, G.-D.: Green synthesis of silver nanoparticles using water extract from galls of Rhus chinensis and its antibacterial activity. J. Clust. Sci. 27, 1737-1750 (2016)
28. Patil, M.P., Palma, J., Simeon, N.C., Jin, X., Liu, X., Ngabire, D., Kim, N.-H., Tarte, N.H., Kim, G.-D.: Sasa borealis leaf extractmediated green synthesis of silver-silver chloride nanoparticles and their antibacterial and anticancer activities. New J. Chem. 41, 1363-1371 (2017)

29. Mock, J.J., Barbic, M., Smith, D.R., Schultz, D.A., Schultz, S.: Shape effects in plasmon resonance of individual colloidal silver nanoparticles. J. Chem. Phys. 116, 6755-6759 (2002)

30. Noginov, M.A., Zhu, G., Bahoura, M., Adegoke, J., Small, C., Ritzo, B.A., Drachev, V.P., Shalaev, V.M.: The effect of gain and absorption on surface plasmons in metal nanoparticles. Appl. Phys. B 86, 455-460 (2007)

31. Rokade, A.A., Patil, M.P., Yoo, S.I., Lee, W.K., Park, S.S.: Pure green chemical approach for synthesis of $\mathrm{Ag}_{2} \mathrm{O}$ nanoparticles. Green Chem. Lett. Rev. 9, 216-222 (2016)

32. Bai, J., Li, Y., Li, M., Wang, S., Zhang, C., Yang, Q.: Electrospinning method for the preparation of silver chloride nanoparticles in PVP nanofiber. Appl. Surf. Sci. 254, 4520-4523 (2008)

33. Tamimi, F., Torres, J., Bettini, R., Ruggera, F., Rueda, C., LopezPonce, M., Lopez-Cabarcos, E.: Doxycycline sustained release from brushite cements for the treatment of periodontal diseases. J. Biomed. Mater. Res. Part A 85, 707-714 (2008)

34. Gade, A., Gaikwad, S., Tiwari, V., Yadav, A., Ingle, A., Rai, M.: Biofabrication of silver nanoparticles by Opuntia ficus-indica: in vitro antibacterial activity and study of the mechanism involved in the synthesis. Curr. Nanosci. 6, 370-375 (2010)

35. Feng, Q.L., Wu, J., Chen, G.Q., Cui, F.Z., Kim, T.N., Kim, J.O.: A mechanistic study of the antibacterial effect of silver ions on Escherichia coli and Staphylococcus aureus. J. Biomed. Mater. Res. 52, 662-668 (2000)

36. Pal, S., Tak, Y.K., Song, J.M.: Does the antibacterial activity of silver nanoparticles depend on the shape of the nanoparticles? Appl. Environ. Microbiol. 73, 1712-1720 (2007)

37. Brown, A., Smith, K., Samuels, T.A., Lu, J., Obare, S., Scott, M.E.: Nanoparticles functionalized with ampicillin destroy multiple antibiotic resistant isolates of Pseudomonas aeruginosa, Enterobacter aerogenes and methicillin resistant Staphylococcus aureus. Appl. Environ. Microbiol. 78, 2768-2774 (2012)

38. Wang, L., Chen, Y.P., Miller, K.P., Cash, B.M., Jones, S., Glenn, S., Benicewicz, B.C., Decho, A.W.: Functionalised nanoparticles complexed with antibiotic efficiently kill MRSA and other bacteria. Chem. Commun. 50, 12030-12033 (2014)

39. Agnihotri, S., Mukherji, S., Mukherji, S.: Size-controlled silver nanoparticles synthesized over the range $5-100 \mathrm{~nm}$ using the same protocol and their antibacterial efficacy. RSC Adv. 4, 3974-3983 (2014)

Publisher's Note Springer Nature remains neutral with regard to jurisdictional claims in published maps and institutional affiliations. 